\title{
Alteration of postprandial glucose and insulin concentrations with meal frequency and composition
}

\author{
Jill A. Kanaley ${ }^{1 *}$, Timothy D. Heden ${ }^{1}$, Ying Liu ${ }^{1}$ and Timothy J. Fairchild ${ }^{2}$ \\ ${ }^{1}$ Department of Nutrition and Exercise Physiology, University of Missouri, 217 Gwynn Hall, Columbia, MO 65211, USA \\ ${ }^{2}$ School of Psychology and Exercise Science, Murdoch University, Murdoch, Western Australia, Australia \\ (Submitted 12 April 2014 - Final revision received 5 June 2014 - Accepted 26 June 2014 - First published online 18 September 2014)
}

\begin{abstract}
A frequent eating pattern may alter glycaemic control and augment postprandial insulin concentrations in some individuals due to the truncation of the previous postprandial period by a subsequent meal. The present study examined glucose, insulin, C-peptide and glucose-dependent insulinotropic peptide (GIP) responses in obese individuals when meals were ingested in a high-frequency pattern (every $2 \mathrm{~h}, 6 \mathrm{M}$ ) or in a low-frequency pattern (every $4 \mathrm{~h}, 3 \mathrm{M}$ ) over $12 \mathrm{~h}$. It also examined these postprandial responses to high-frequency, high-protein meals $\left(6 \mathrm{M}_{\mathrm{HP}}\right)$. In total, thirteen obese subjects completed three $12 \mathrm{~h}$ study days during which they consumed $6276 \mathrm{~kJ}$ (1500 kcal): (1) $3 \mathrm{M}-15 \%$ protein and $65 \%$ carbohydrate; (2) $6 \mathrm{M}-15 \%$ protein and $65 \%$ carbohydrate; (3) $6 \mathrm{M}_{\mathrm{HP}}-45 \%$ protein and $35 \%$ carbohydrate. Blood samples were collected every $10 \mathrm{~min}$ and analysed for glucose, insulin, C-peptide and GIP. Insulin total AUC (tAUC) and peak insulin concentrations $(P<0.05)$ were higher in the $3 \mathrm{M}$ condition than in the $6 \mathrm{M}$ condition, but there were no differences in glucose tAUC between the conditions. The $6 \mathrm{M}_{\mathrm{HP}}$ regimen (glucose: 3569 (SE 83) $\mathrm{mmol} / \mathrm{l} \times \mathrm{min}(64.3$ (SE 1.5) $\mathrm{g} / \mathrm{dl} \times \mathrm{min})$, insulin: 1.577 ( $\mathrm{sE} 0 \cdot 146) \mathrm{pmol} / \mathrm{l}(22 \cdot 7$ (sE 2.1) $\mu \mathrm{IU} / \mathrm{dl}$ ) for $12 \mathrm{~h}$ ) lowered glucose and insulin excursions more so over $12 \mathrm{~h}$ than either the $3 \mathrm{M}$ regimen (glucose:

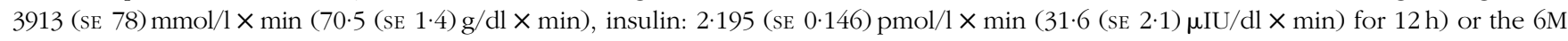
regimen (glucose: $3902(\mathrm{sE} 83) \mathrm{mmol} / 1 \times \min (70.3(\mathrm{SE} 1.5) \mathrm{g} / \mathrm{dl} \times \mathrm{min})$, insulin: $1.861(\mathrm{sE} 0.174) \mathrm{pmol} / 1 \times \mathrm{min}(26.8(\mathrm{sE} 2.5) \mu \mathrm{IU} / \mathrm{dl} \times \mathrm{min})$ for $12 \mathrm{~h} ; P<0 \cdot 01)$. Insulin secretion, GIP concentrations and the glucose:insulin ratio were not altered by meal frequency or composition. In obese subjects, ingestion of meals in a low-frequency pattern does not alter glucose tAUC, but increases postprandial insulin responses. The substitution of carbohydrates with protein in a frequent meal pattern results in tighter glycaemic control and reduced postprandial insulin responses.
\end{abstract}

\section{Key words: Meal test: Glucose-dependent insulinotropic peptide: Obesity: Frequent feeding: Insulin secretion}

A high fasting insulin concentration commonly exists with obesity, impaired glucose tolerance and type 2 diabetes $(\mathrm{T} 2 \mathrm{D})^{(1-3)}$. There is evidence in Zucker rats that the onset of hyperinsulinaemia precedes the development of obesity and muscle insulin resistance and the magnitude of hyperinsulinaemia is proportional to the duration of obesity ${ }^{(4)}$. In addition, obese rats treated with diazoxide (inhibits insulin release) were found to exhibit reduced weight gain and improved glucose tolerance ${ }^{(5)}$. Subsequent research ${ }^{(6)}$ in obese human subjects with hyperinsulinaemia demonstrated that administration of diazoxide over 8 weeks led to attenuation of hyperinsulinaemia, greater weight loss, and greater decrease in body fat and reduced the acute insulin response to glucose, without inducing glucose intolerance. Based on these findings, it has been hypothesised that hyperinsulinaemia may play a more prominent role in the development of obesity, insulin resistance and T2D than previously thought and that therapies alleviating hyperinsulinaemia should be targeted for the prevention of these chronic conditions ${ }^{(7-9)}$.

Although numerous conditions and factors are known to increase mean insulin concentrations, the most apparent and modifiable factor is diet - in particular, the macronutrient composition of the diet and the pattern (frequency of meals per $\mathrm{d}$ ) of energy intake. A more frequent eating pattern was shown to result in prolonged periods of hyperglycaemia and/or hyperinsulinaemia in healthy individuals ${ }^{(10)}$, which is suggested to be a result of truncating the postprandial period with a subsequent meal, thereby maintaining consistently high insulin concentrations throughout the day. Previously, we had also observed elevated glucose AUC throughout the day with ingestion of six meals than with that of three meals over $12 \mathrm{~h}(P<0 \cdot 05)$, while insulin AUC was reduced ${ }^{(11)}$. However,

Abbreviations: 3M, low-frequency meals; $6 \mathrm{M}$, high-frequency meals; $6 \mathrm{M}_{\mathrm{HP}}$, high-frequency, high-protein meals; GIP, glucose-dependent insulinotropic peptide; HOMA-IR, homeostatic model assessment of insulin resistance; QUICKI, quantitative insulin sensitivity check index; T2D, type 2 diabetes; tAUC, total AUC.

* Corresponding author: J. A. Kanaley, fax +1 573884 4885, email kanaleyj@missouri.edu 
Solomon $e a{ }^{(12)}$ found no difference in insulin or glucose total AUC (tAUC) over an $8 \mathrm{~h}$ period when comparing a low-feeding frequency pattern (two meals per d) with a high-feeding frequency pattern (twelve meals per d) in lean individuals. One limitation of these studies has been the recruitment of only non-obese, healthy individuals. Jenkins et al. ${ }^{(13)}$ reported that spreading the nutrient load (three meals and one snack $v$. thirteen snacks) resulted in reduced glucose, insulin and C-peptide concentrations in older (age range: 37-81 years), overweight (106-129\% overweight) patients with T2D. Taken together, these studies suggest a divergent response to increased meal frequency in lean individuals $v$. overweight individuals with T2D; thus, re-examination of this question would be prudent in a more homogeneous population to identify the influence of obesity alone.

Given the paucity of research examining the impact of meal frequency on glucose and insulin concentrations in obese individuals $^{(12,13)}$, the purpose of the present study was to examine postprandial glucose and insulin responses when meals are separated by $2 v .4 \mathrm{~h}$ in obese individuals over a $12 \mathrm{~h}$ period. More specifically, we were interested in determining insulin concentrations in this population in response to altered meal frequency regimens. We speculated that shorter intervals between meals would result in prolonged hyperglycaemia with concomitant lower insulin concentrations due to altered insulin secretion in obese individuals.

The substitution of carbohydrates with protein also decreases postprandial glucose and insulin responses in both the short term $^{(14)}$ and longer term ${ }^{(15)}$; therefore, meal composition must also be considered. Lan-Pidhainy \& Wolever $^{(16)}$ reported that a high-protein meal $(30 \mathrm{~g})$ increased the insulin response, but had no effect on insulin secretion rate. Therefore, the second purpose of the present study was to establish the postprandial insulin response to frequent ingestion of high-protein meals over $12 \mathrm{~h}$ in obese individuals. We hypothesised that substituting carbohydrates with protein during a high-frequency meal pattern would reduce glucose concentrations, resulting in decreased insulin AUC and secretion rates.

\section{Experimental methods}

\section{Subjects}

A total of thirteen obese men and women (age: $29-50$ years) with a fasting blood glucose concentration $(<5.55 \mathrm{mmol} / \mathrm{l}$; $<100 \mathrm{mg} / \mathrm{dl}$ ) were recruited for the present study. The study was conducted according to the guidelines laid down in the Declaration of Helsinki, and all procedures involving human subjects were approved by the Institutional Review Board of the University of Missouri. Written informed consent was obtained from all subjects. Obese individuals with BMI $30-45 \mathrm{~kg} / \mathrm{m}^{2}$, waist circumference $>88 \mathrm{~cm}$, and body fat percentage $>35 \%$, with no smoking history, having a sedentary lifestyle $(<60 \mathrm{~min}$ of physical activity per week), who were not pregnant, and having no prior history of heart, lung, kidney, endocrine, or liver disease were eligible to participate in the study ${ }^{(17)}$. No subject was taking any prescription medications known to alter glucose or lipid metabolism and was weight stable over the last 6 months. Baseline information about dietary intake, physical activity and medical history was obtained via a self-reported questionnaire.

\section{Study design}

Parts of the experimental design have been published previously $^{(17)}$. All subjects completed three $12 \mathrm{~h}$ study days during which they consumed $6276 \mathrm{~kJ}$ (1500 kcal). The following regimens were used: a low-frequency meal regimen (three meals $(3 \mathrm{M})$ : $2092 \mathrm{~kJ} / \mathrm{meal}$ ( $500 \mathrm{kcal} / \mathrm{meal}: 18.8 \mathrm{~g}$ protein, $81.2 \mathrm{~g}$ carbohydrate, and $10 \mathrm{~g}$ fat) consumed every $4 \mathrm{~h}$ ); a high-frequency meal regimen (six meals (6M): $1046 \mathrm{~kJ}(250 \mathrm{kcal} / \mathrm{meal}: 9.4 \mathrm{~g}$ protein, $40.6 \mathrm{~g}$ carbohydrate, and $5 \mathrm{~g}$ fat) consumed every $2 \mathrm{~h}$ ); high-frequency, high-protein meals $\left(6 \mathrm{M}_{\mathrm{HP}}\right): 1046 \mathrm{~kJ} / \mathrm{meal}(250 \mathrm{kcal} / \mathrm{meal}: 28 \mathrm{~g}$ protein, $21.9 \mathrm{~g}$ carbohydrate, and $5 \mathrm{~g}$ fat) consumed every $2 \mathrm{~h}$. Approximately 1 month elapsed between each study day, and the three study days were completed in a counterbalanced order. The study days were energy-matched. The meals comprised a liquid shake (Nutritional Shake, Walgreens). In the $6 \mathrm{M}_{\mathrm{HP}}$ regimen, protein was included, which consisted of Pro Complex whey protein (Pro Complex, Optimum Nutrition, Inc.) $)^{(11)}$ and branched-chain amino acids and also contained a small amount of fat (approximately $2 \mathrm{~g}$ ) sufficient to balance the fat component of the dietary conditions at $20 \%$. Liquid meals were used for this protocol, as previous work has shown that alterations in the macronutrient composition of liquids do not affect gastric emptying rate ${ }^{(18)}$ and so that the rate of eating could be more precisely controlled, thereby eliminating the effect of eating speed on glucose and insulin responses.

\section{Study days}

Following a $12 \mathrm{~h}$ overnight fast, a venous catheter was placed into the antecubital vein and kept patent with a saline drip. Blood samples were drawn from a stopcock at baseline and every $10 \mathrm{~min}$ for $12 \mathrm{~h}$. The meals were consumed at 07.00 hours (following baseline sample collection), 11.00 and 15.00 hours on the $3 \mathrm{M}$ day and at 07.00, 09.00, 11.00, 13.00, 15.00 and 17.00 hours on the $6 \mathrm{M}$ day. The subjects were sedentary throughout the day with only minor activity. Blood samples were analysed for glucose, insulin, C-peptide and glucose-dependent insulinotropic peptide (GIP).

\section{Anthropometric measures}

As part of the screening, all subjects had their height and weight measured using a digital scale and a stadiometer. Waist and hip circumferences were measured using a measuring tape. Body fat percentage was calculated using the BOD POD ${ }^{\circledR}$ according to the manufacturer's guidelines (Cosmed Corporation). Lung volume was measured and body fat was estimated using the Siri equation.

\section{Dietary intake assessment}

As prior dietary patterns can influence postprandial responses, the subjects were required to keep a dietary record during the 
$3 \mathrm{~d}$ before each $12 \mathrm{~h}$ visit. The dietary record from the 1 st study day was given to the subjects on their subsequent visit and they were asked to repeat the same dietary pattern before the subsequent visit ${ }^{(17)}$. Total energy content and macro/ micronutrient content were determined from the records using Food Processor SQL, version 10.8 (ESHA Research).

\section{Blood handling and analysis}

Blood samples were placed in serum separator tubes, centrifuged at $3000 \mathrm{rpm}$ for $15 \mathrm{~min}$ and stored at $-80^{\circ} \mathrm{C}$ until analysis. Blood glucose concentrations were determined using colorimetric assays (Fischer Scientific, Inc.) (CV - 1.8\%). Serum insulin concentrations were determined using the Immulite 1000 Immunoassay System (Siemens Healthcare Diagnostics, Inc.). C-peptide and GIP concentrations were determined with kits from Millipore using Luminex xMap Technology (Linco Research) on a Luminex 100/200 platform (Luminex Corporation). Inter-assay CV for insulin, C-peptide and GIP were $8.3,7.9$ and $9 \%$, and intra-assay CV for insulin, C-peptide and GIP were $6.9,8.2$ and $7.9 \%$, respectively. All samples for a given subject were run in the same assay.

\section{Statistical analyses}

The homeostatic model assessment of insulin resistance (HOMA-IR) $^{(19)}$ and quantitative insulin sensitivity check index (QUICKI) ${ }^{(20)}$ were used to calculate insulin resistance and sensitivity, respectively, before each condition. The tAUC for postprandial responses over $12 \mathrm{~h}$ was calculated using the trapezoidal method ${ }^{(21)}$. Postprandial glycaemic and insulin excursions were derived from the absolute difference in nadir (baseline insulin concentrations before each meal) and peak concentrations.

Insulin secretion was determined using the C-peptide data. A pulse profile was analysed using a multi-parameter deconvolution technique (AutoDecon, Pulse_XP software; University of Virginia) that derives quantitative estimates of attributes of C-peptide secretory pulses and half-life from measured C-peptide concentrations ${ }^{(22,23)}$. A Gaussian distribution of secretory rate was assumed using the serum C-peptide concentration value and it was assumed to match insulin concentration at a 1:1 ratio. Basal secretion was estimated for each condition. C-peptide pulses were considered significant if they were able to be distinguished from zero with a 95\% statistical significance as reported previously ${ }^{(22,24)}$.

Statistical analyses were carried out using Statistical Package for the Social Sciences statistical software, version 19.0 (IBM, Inc.). For the primary analysis, a mixed-model ANOVA with repeated measures was used to compare the tAUC values between the conditions for all variables, and the baseline value on each study day for each respective hormone was used as a covariate. As baseline values can influence the hormonal response, correction for the baseline value of each subject was performed to control for day-to-day variation. Variables for the deconvolution analysis were also analysed with an AVOVA with repeated measures. A Pearson product correlation was run on the hormone variables. Statistical significance was set at $P \leq 0.05$, and values are reported as means with their standard errors.

For the bootstrapping analysis, each subject's hormone concentration at each time point from one study day was subtracted from that on the comparison study day at the same time point (e.g. $3 \mathrm{M}-6 \mathrm{M})^{(25)}$. The change in hormone concentrations was plotted over time with simultaneous 95\% confidence bands. The 95\% confidence regions were derived using the bootstrapping technique. This 95\% confidence region avoids the problem of multiple point-wise comparisons. A significant response was defined as occurring when the lower 95\% confidence limit for the curve was greater than zero, and a significant suppression of hormone release was defined as occurring when the upper $95 \%$ confidence limit for the regression curve was less than zero ${ }^{(25)}$. This analysis was carried out for each study day for glucose and insulin concentrations.

\section{Results}

In total, eleven women and three men completed the study. No significant differences were found in fasting glucose, insulin, C-peptide or GIP concentrations between the study days. The mean fasting insulin concentration across the three study days was 68.8 (SE 6.9) pmol/1 (9.9 (SE 1.0) $\mu \mathrm{IU} / \mathrm{ml})$, while the mean fasting glucose concentration was 4.48 (SE $0 \cdot 122) \mathrm{mmol} / \mathrm{l}(80 \cdot 8$ ( $\mathrm{sE} 2 \cdot 2) \mathrm{mg} / \mathrm{dl}$ ). The subjects remained weight stable during the study and weighed 100.0 (sE 3.7) kg (weight gain/loss $<2 \mathrm{~kg}$ ) and had a BMI of $35.5(\mathrm{se} 1.0) \mathrm{kg} / \mathrm{m}^{2}$. They had a mean body fat percentage of 45.9 (SE 1.8) \%. Their HOMA-IR was $2 \cdot 1$ (SE $0 \cdot 2$ ) and insulin sensitivity (QUICKI) was 0.32 (SE 0.05). There were no dietary differences (energy consumed or composition) during the $3 \mathrm{~d}$ before each condition. The subjects consumed approximately $10460 \mathrm{~kJ}$ (2500 kcal) during each of the $3 \mathrm{~d}$ before the study day ( $48 \%$ carbohydrate, $15 \%$ protein and $37 \%$ fat $)^{(17)}$.

The patterns of postprandial glucose and insulin responses over the $12 \mathrm{~h}$ period are shown in Fig. 1(a) and (b), respectively. There were no differences in glucose tAUC adjusted for fasting glucose concentrations between the $3 \mathrm{M}$ and $6 \mathrm{M}$ regimens $(P=0.98$; Fig. 2(a)), but postprandial changes in peak glucose concentrations were greater in the $3 \mathrm{M}$ condition at the first meal $(2 \cdot 18(\mathrm{SE} 0 \cdot 27) \mathrm{mmol} / \mathrm{l} ; 39 \cdot 2(\mathrm{SE} 4.8) \mathrm{mg} / \mathrm{dl})$ than in both the $6 \mathrm{M}$ and $6 \mathrm{M}_{\mathrm{HP}}$ conditions (1.53 (SE 0.21) and $0.87(\mathrm{se} 0 \cdot 16) \mathrm{mmol} / \mathrm{l}(27.5$ (SE 3.7) and 15.6 (sE 2.9) $\mathrm{mg} / \mathrm{dl}$ ), respectively, $P<0.0001$ ) (Fig. 1(a)). Postprandial changes in peak glucose concentrations were also significantly greater in the $6 \mathrm{M}$ condition than in $6 \mathrm{M}_{\mathrm{HP}}$ condition $(P<0 \cdot 001$; Fig. $1(\mathrm{a}))$. Within each study day, there was no significant difference in the change in peak concentrations with each meal, and thus the glucose response at subsequent meals did not differ from that at the first meal after $12 \mathrm{~h}$ of fasting. Comparison of the postprandial glucose response on the $3 \mathrm{M}$ day with that on the $6 \mathrm{M}$ day revealed periods of higher glucose concentrations on the $3 \mathrm{M}$ day $(07.30-07.40,07.50-08.00,12.20-12.40$, $13.00-13.20,15.50-16.00$, and 16.20-17.20 hours; total $130 \mathrm{~min} / \mathrm{d}$ ) (Fig. 3(a)) and lower glucose concentrations (the lines passing below the $x$-axis) at the second, fourth and fifth meals (09.20-09.40, 13.30-15.10, and 17.30-19.00 hours; 

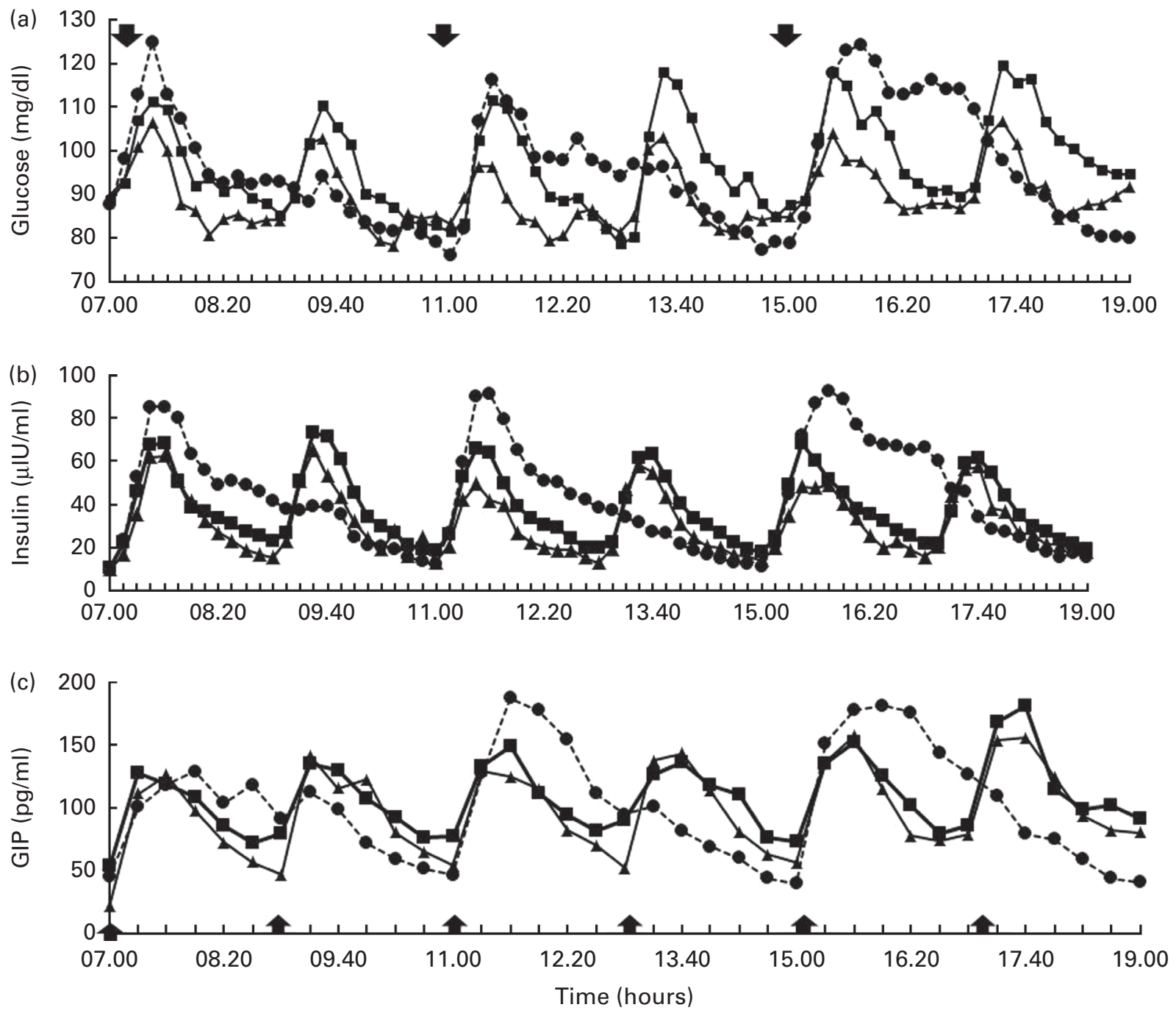

Fig. 1. Patterns of (a) glucose, (b) insulin and (c) glucose-dependent insulinotropic peptide (GIP) responses over $12 \mathrm{~h}$ for each study day. Values are means ( $n$ 13, two men/eleven women), with their standard errors. -..., low-frequency meals; _To convert glucose in $\mathrm{mg} / \mathrm{dl}$ to $\mathrm{mmol} / \mathrm{l}$, multiply by 0.0555 . To convert insulin in $\mu \mathrm{IU} / \mathrm{ml}$ to $\mathrm{pmol} / \mathrm{l}$, multiply by 6.945 .

total $210 \mathrm{~min} / \mathrm{d}$ ), indicating that overall glucose concentrations were lower for longer periods of time during the day while on the $3 \mathrm{M}$ regimen.

Insulin tAUC adjusted for fasting insulin concentrations was higher during the $3 \mathrm{M}$ regimen than during the $6 \mathrm{M}$ regimen $(P<0.05$; Fig. 2(b)). Postprandial insulin excursions on the $3 \mathrm{M}$ day (mean: 637 (sE 93.7) pmol/1; 91.8 (SE 13.5) $\mu \mathrm{IU} / \mathrm{ml}$ ) were significantly greater $(P<0 \cdot 001)$ at all meals than those on the $6 \mathrm{M}$ day (mean: 384 ( $\mathrm{se} 75) \mathrm{pmol} / \mathrm{l} ; 55 \cdot 3$ (se 10.8) $\mu \mathrm{IU} / \mathrm{ml}$ ). Insulin concentrations closely followed meal ingestion: insulin concentrations on the $3 \mathrm{M}$ day were higher than those on the $6 \mathrm{M}$ day at time points that corresponded with meal ingestion (07.20-09.10, 11.30-13.20, and 15.40-17.20 hours; total $320 \mathrm{~min} / \mathrm{d}$ ) (Fig. 3(b)), while higher insulin concentrations were observed on the $6 \mathrm{M}$ day only at those intervals when additional meals were consumed (09.20-11.10, 13.30-15.10, and $17.30-18.50$ hours; total $290 \mathrm{~min} / \mathrm{d}$ ), indicating that insulin concentrations were higher for slightly longer periods of time while on the $3 \mathrm{M}$ regimen.
Examination of the tAUC for each meal revealed that on the $3 \mathrm{M}$ and $6 \mathrm{M}$ days there was no significant difference across the meals in glucose or insulin tAUC at each respective meal, although there was a trend for slightly lower glucose tAUC for the meals ingested earlier in the day than for those ingested later in the day. Insulin tAUC exhibited a similar trend in the $3 \mathrm{M}$ condition, but not in the $6 \mathrm{M}$ condition.

The $6 \mathrm{M}_{\mathrm{HP}}$ condition resulted in a significantly lower glucose tAUC compared with both the $3 \mathrm{M}$ and $6 \mathrm{M}$ conditions $(P<0 \cdot 01$ and $P<0.01$, respectively) (Fig. 2(a)). Peak glucose concentrations on the $6 \mathrm{M}_{\mathrm{HP}}$ day were significantly lower $(P<0 \cdot 01)$ than those on the $3 \mathrm{M}$ day and approached significance on the $6 \mathrm{M}$ day $(P<0 \cdot 06)$. Insulin tAUC was greater on both the $6 \mathrm{M}$ and $3 \mathrm{M}$ days than on the $6 \mathrm{M}_{\mathrm{HP}}$ day $(P<0.0001$; Fig. 2(b)). Peak insulin responses were greater on the $3 \mathrm{M}$ day than on the $6 \mathrm{M}_{\mathrm{HP}}$ day at each corresponding meal of the $3 \mathrm{M}$ day $(P<0 \cdot 01)$, but peak insulin responses on the $6 \mathrm{M}$ day were significantly greater only at the third and fifth meals than those on the $6 \mathrm{M}_{\mathrm{HP}}$ day $(P<0.01$; Fig. 1(b)). 

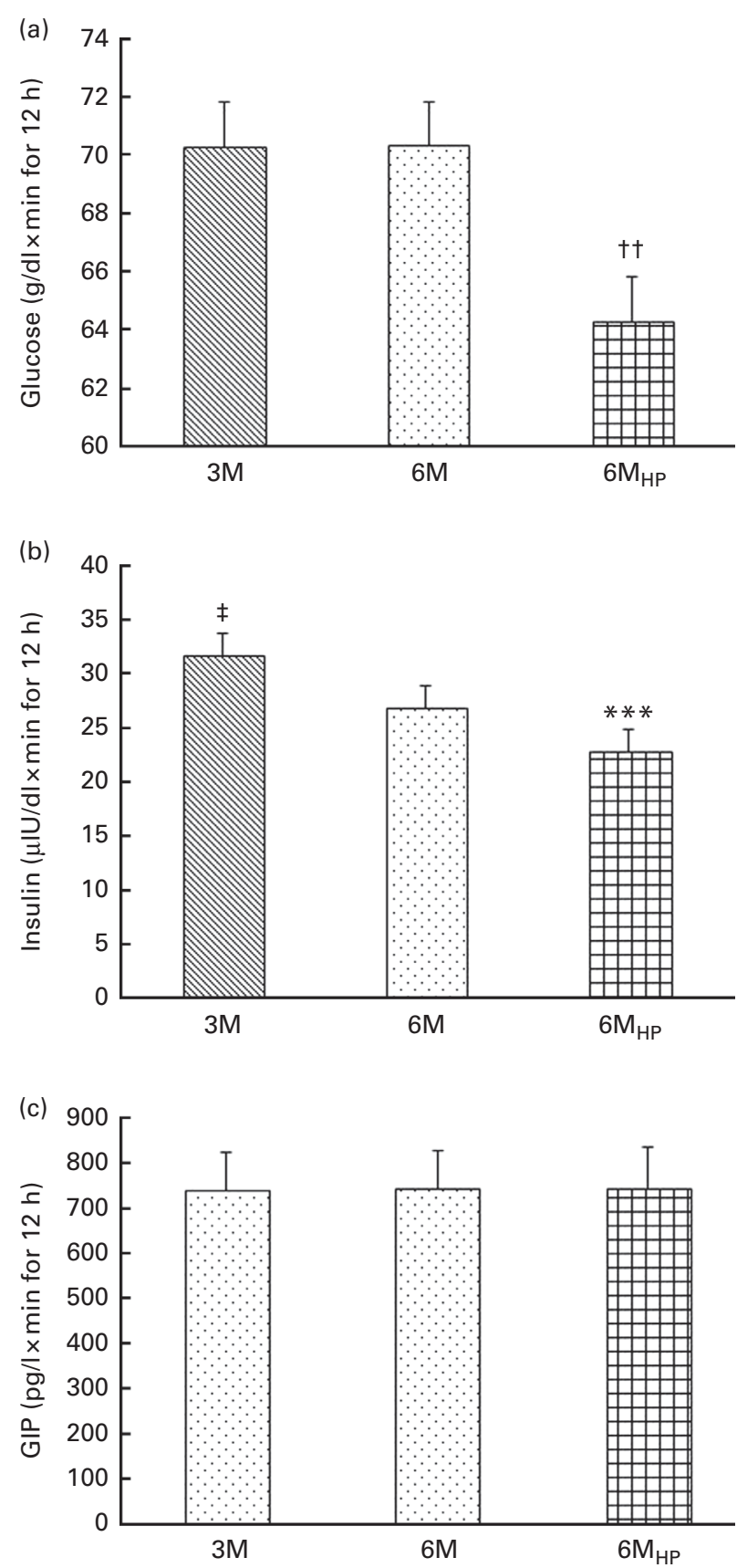

Fig. 2. Total AUC adjusted for fasting (a) glucose, (b) insulin and (c) glucose-dependent insulinotropic peptide (GIP) concentrations. 3M, low-frequency meals; $6 \mathrm{M}$, high-frequency meals; $6 \mathrm{M}_{\mathrm{HP}}$, high-frequency, highprotein meals. Values are means ( $n 13$, two men/eleven women), with their standard errors represented by vertical bars. ${ }^{* * \star}$ Mean value was significantly different from those during the $3 \mathrm{M}$ and $6 \mathrm{M}$ regimens $(P<0.001)$. $\dagger+$ Mean value was significantly different from those during the $3 \mathrm{M}$ and $6 \mathrm{M}$ regimens $(P<0.01)$. $\ddagger$ Mean value was significantly different from that during the $6 \mathrm{M}$ regimen $(P<0.05)$. To convert glucose in $\mathrm{g} / \mathrm{dl}$ to $\mathrm{mmol} / \mathrm{l}$, multiply by 55.5 . To convert insulin in $\mu \mathrm{lU} / \mathrm{dl}$ to $\mathrm{pmol} / \mathrm{l}$, multiply by 0.06945 .

The contrast in glycaemic and insulin excursions during the $6 \mathrm{M}_{\mathrm{HP}}$ regimen compared with those during the $6 \mathrm{M}$ and $3 \mathrm{M}$ regimens is shown in Fig. 4. Compared with those in the $6 \mathrm{M}$ condition, glucose concentrations in the $6 \mathrm{M}_{\mathrm{HP}}$ condition were usually lower for about $50 \mathrm{~min}$ after meal ingestion
(Fig. 4(a)), while insulin concentrations were lower at the second, third and fourth meals and for very short periods of time at the fifth and sixth meals (Fig. 4(b)). In comparison with those in the $3 \mathrm{M}$ condition, glucose concentrations in the $6 \mathrm{M}_{\mathrm{HP}}$ condition were lower for approximately $80 \mathrm{~min}$ after meal ingestion at the first, third and fifth meals (Fig. 4(c)). Insulin concentrations followed a very similar trend of being much higher in the $3 \mathrm{M}$ condition for approximately $2 \mathrm{~h}$ after meal ingestion (Fig. $4(\mathrm{~d})$ ). In the $6 \mathrm{M}_{\mathrm{HP}}$ condition, there were no differences in glucose and insulin tAUC across the meals on the study day.

The highest glucose:insulin ratio occurred at fasting and immediately before ingestion of each meal (Fig. 5(a)). After meal ingestion, this ratio dropped rapidly as the magnitude of increase in insulin concentrations was greater than that of increase in glucose concentrations. Approximately $40 \mathrm{~min}$ after meal ingestion, the ratio began to rise under all conditions. The slope of this rise between 40 and $120 \mathrm{~min}$ after
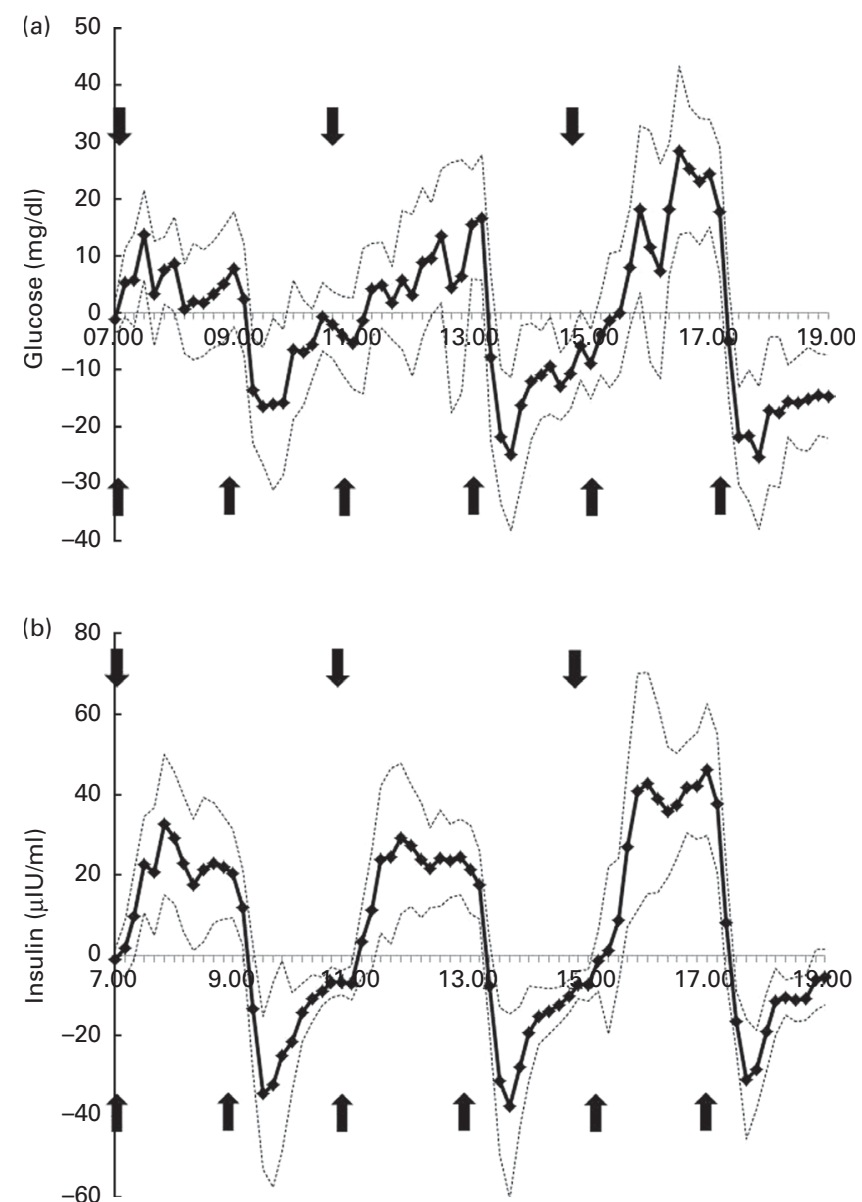

Fig. 3. Comparison of the low-frequency meal and the high-frequency meal days for (a) glucose and (b) insulin concentrations over $12 \mathrm{~h}$. The difference between the study days (-) and simultaneous $95 \%$ confidence limits (......) are shown. Significant stimulation of glucose or insulin release by the meal occurred when the lower $95 \%$ confidence limit was greater than zero. Significant suppression of glucose or insulin release occurred when the upper $95 \%$ confidence limit was less than zero. T, Meal. To convert glucose in $\mathrm{mg} / \mathrm{dl}$ to $\mathrm{mmol} / \mathrm{l}$, multiply by 0.0555 . To convert insulin in $\mu \mathrm{IU} / \mathrm{ml}$ to $\mathrm{pmol} / \mathrm{l}$, multiply by 6.945 . 
(a)

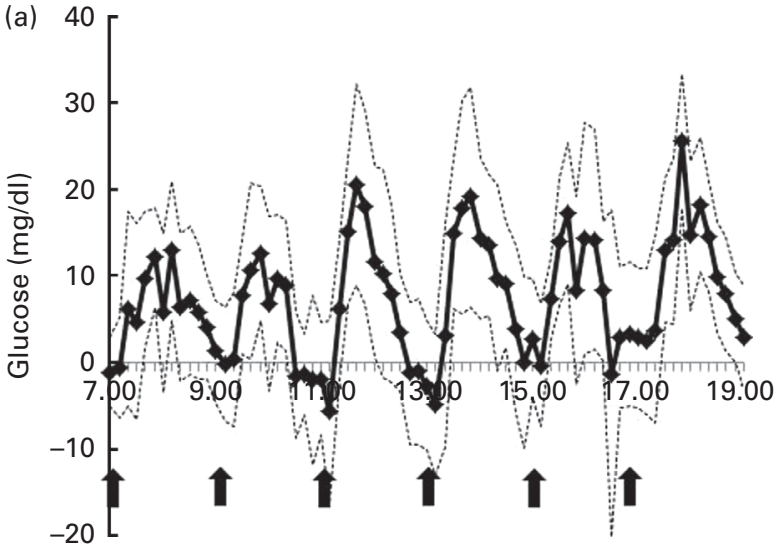

(c)

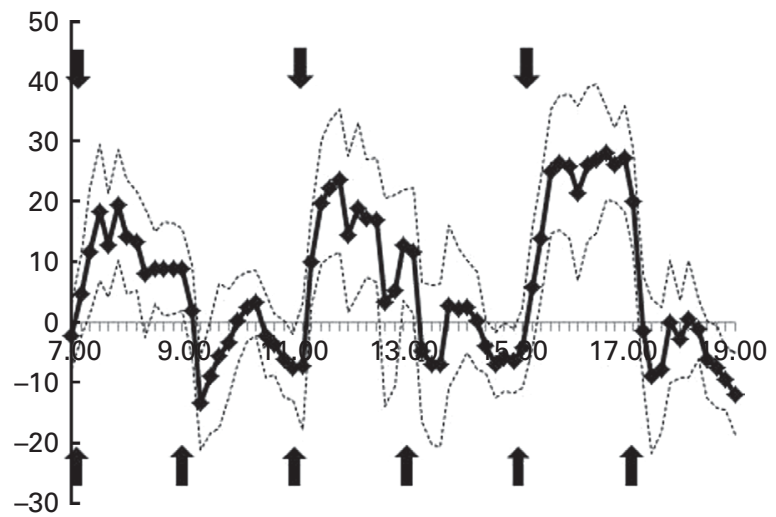

(d)

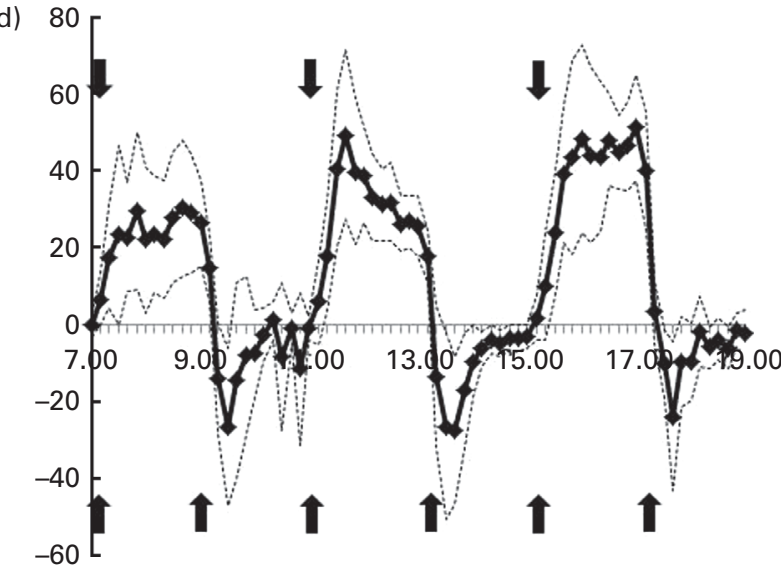

Fig. 4. Comparison of the high-frequency meal minus high-frequency, high-protein meal $\left(6 \mathrm{M}_{\mathrm{HP}}\right)$ and low-frequency meal minus $6 \mathrm{M}_{\mathrm{HP}}$ days for (a, c) glucose and $(b, d)$ insulin concentrations, respectively, over $12 \mathrm{~h}$. More details are given in Fig. 3. $\mathbf{t}$, Meal. To convert glucose in $\mathrm{mg} / \mathrm{dl}$ to $\mathrm{mmol} / \mathrm{l}, \mathrm{multiply} \mathrm{by} 0.0555$. To convert insulin in $\mu \mathrm{lU} / \mathrm{ml}$ to $\mathrm{pmol} / \mathrm{l}$, multiply by 6.945 .

meal ingestion demonstrated a condition effect, such that a significantly lower slope was observed in the $3 \mathrm{M}$ condition than in the $6 \mathrm{M}_{\mathrm{HP}}(P<0.01)$ and $6 \mathrm{M}(P<0.05)$ conditions. There was no difference in the slope between the $6 \mathrm{M}$ and $6 \mathrm{M}_{\mathrm{HP}}$ conditions. Furthermore, there was no difference in this effect between the meals across the day.

There were no differences in C-peptide and GIP tAUC between the study days for meal frequency or composition. The pattern of GIP response is shown in Fig. 1(c), and as can be seen from the tAUC, the response was very similar across all the study days (Fig. 2(c)). Deconvolution of the C-peptide data provided insights into insulin secretion characteristics for the $12 \mathrm{~h}$ period. There were no differences in insulin secretion characteristics between the study days (Table 1). Fasting GIP and C-peptide concentrations were significantly correlated with insulin tAUC $(r 0.449, P<0.01$ and $r 0.751, P<0.000$, respectively).

\section{Discussion}

The eating regimen of frequent meals has become common practice, but the impact of such an eating pattern on glycaemic and insulinaemic excursions over the course of a $12 \mathrm{~h}$ period has not been well studied, particularly in obese individuals who often demonstrate hyperinsulinaemia while being normoglycaemic. The findings from the present study show, for the first time, that in obese individuals: (1) larger less frequent meals (3M) result in greater insulin responses (peak insulin concentrations and $12 \mathrm{~h}$ AUC) than what is observed with a 6M pattern; (2) while peak glucose concentrations were higher during the $3 \mathrm{M}$ regimen, glucose concentrations remained largely unaffected by the pattern $(3 \mathrm{M} v$. 6M) of energy intake during the study day; (3) substituting carbohydrates with protein reduced glucose and insulin concentrations substantially throughout the day; (4) insulin secretion and insulin clearance were not altered by acute changes in meal frequency or composition.

While glucose tAUC was not different between the $3 \mathrm{M}$ and $6 \mathrm{M}$ regimens, the postprandial responses to meals were very different between the conditions. The $3 \mathrm{M}$ pattern had a larger energy and carbohydrate load/meal, thus resulting in higher peak glucose concentrations after meal ingestion and for a number of short intervals throughout the day. Peak glucose values were $30 \%$ higher following the ingestion of the initial meal on the $3 \mathrm{M}$ day than on the $6 \mathrm{M}$ day, but no differences were observed after the ingestion of subsequent meals. This observation contrasts our early finding in healthy young individuals that a $6 \mathrm{M}$ pattern resulted in higher glucose 
Table 1. Deconvolution parameters for C-peptide

(Mean values with their standard errors, $n$ 13)

\begin{tabular}{|c|c|c|c|c|c|c|}
\hline & \multicolumn{2}{|c|}{ LFM } & \multicolumn{2}{|c|}{ HFM } & \multicolumn{2}{|c|}{$\mathrm{HF}_{\mathrm{HP}}$} \\
\hline & Mean & SE & Mean & SE & Mean & SE \\
\hline Secretory pulses (pulses/12 h) & $5 \cdot 4$ & 0.5 & $6 \cdot 7$ & 0.4 & $6 \cdot 1$ & 0.5 \\
\hline Half-width (nmol/l) & $20 \cdot 9$ & $4 \cdot 0$ & $12 \cdot 2$ & $1 \cdot 5$ & $16 \cdot 3$ & 3.4 \\
\hline Half-life (min) & 71.9 & $8 \cdot 6$ & $67 \cdot 2$ & $8 \cdot 4$ & $69 \cdot 4$ & $7 \cdot 3$ \\
\hline Pulse mass (nmol/l per pulse) & 4929 & 945 & 4189 & 686 & 5319 & 972 \\
\hline Peak amplitude (nmol/l per pulse) & 405 & 94 & 417 & 96 & 573 & 210 \\
\hline Pulse interval (min) & $140 \cdot 5$ & $16 \cdot 1$ & $111 \cdot 7$ & $10 \cdot 2$ & $112 \cdot 4$ & $6 \cdot 3$ \\
\hline Production rate (mass/pulse) & 23859 & 3793 & 26718 & 4465 & 28717 & 7135 \\
\hline
\end{tabular}

LFM, low-frequency meals; HFM, high-frequency meals, HP, high protein.

concentrations across the day ${ }^{(11)}$. However, the findings parallel with those of Solomon et al. ${ }^{(12)}$, who compared glucose/insulin responses between meals consumed at a low frequency (every $4 \mathrm{~h}$ ) or a high frequency (every $40 \mathrm{~min}$ ) for 8 h. Similarly, Munsters \& Saris ${ }^{(10)}$ demonstrated greater insulin and glucose fluctuations but lower glucose AUC in healthy young men, following the ingestion of a low-frequency diet (three meals per d) or a high-frequency diet (fourteen meals per $\mathrm{d}$ ).

Despite equivalent glucose concentrations, overall insulin concentrations tended to be approximately $10 \%$ higher on the $3 \mathrm{M}$ day, and this finding is in line with previous data from our laboratory ${ }^{(17)}$. The large insulin excursions closely tracked when the meals were ingested (Fig. 3) on each of the respective days, but insulin responses were greater on the $3 \mathrm{M}$ day for about $390 \mathrm{~min}$ across the day while being greater on the $6 \mathrm{M}$ day for $290 \mathrm{~min}$. Thus, if the hypothesis regarding chronically elevated insulin concentrations as being deleterious ${ }^{(8,26)}$ holds true, then meals that are high in carbohydrates consumed in a $6 \mathrm{M}$ pattern may be beneficial for obese individuals, particularly if they have elevated insulin responses to meals. Future long-term studies manipulating meal frequency need to be conducted to establish the longterm effects that this may have on insulin secretion and/or insulin resistance in a variety of populations.

A number of studies have reported diurnal variations in glucose tolerance in lean individuals ${ }^{(27,28)}$, which may be a circadian variation in the responsiveness of $\alpha$-cells to glucose, resulting in an attenuation in insulin sensitivity later in the day $^{(28)}$. However, in obese subjects, this circadian variation is believed to be absent ${ }^{(29)}$, which is supported by our data. Although we did not include direct measures of insulin sensitivity, there were only slight differences in postprandial insulin or glucose concentrations or the glucose:insulin ratio in response to subsequent meals throughout the day in each of the dietary conditions studied. Slight divergences between glucose and insulin responses throughout the day are expected, and these divergences may be more apparent in obese individuals, as it is often not uncommon to find normal glucose responses in this population but higher insulin concentrations to achieve these levels.

We also tested the hypothesis that substituting carbohydrates with protein would lower postprandial blood glucose and insulin responses. As expected, there was a significant decrease in the absolute concentrations of blood glucose and insulin in response to the $6 \mathrm{M}_{\mathrm{HP}}$ condition in the present study, which is most probably due to the reduced total carbohydrate load. When compared with the $6 \mathrm{M}$ condition, the $6 \mathrm{M}_{\mathrm{HP}}$ condition resulted in lower glucose concentrations for approximately $310 \mathrm{~min}$ (approximately $43 \%$ of the day) over the $12 \mathrm{~h}$ period, while insulin concentrations were lower about $260 \mathrm{~min}$ (approximately 36\%) throughout the day. The insulinotropic effects of protein are well characterised in the literature. Frid et $a l$. ${ }^{(30)}$ demonstrated that addition of whey protein to meals containing rapidly digested and absorbed carbohydrates resulted in an insulinotropic effect, thereby reducing glucose concentrations. Notably, however, Lan-Pidhainy \& Wolever ${ }^{(16)}$ demonstrated postprandial hyperinsulinaemia only when $30 \mathrm{~g}$ of protein are consumed. In the present study, the subjects ingested approximately $28 \mathrm{~g}$ of whey protein in the $6 \mathrm{M}_{\mathrm{HP}}$ condition. When assessing the deconvolution parameters for C-peptide, there appeared to be no change in any of the secretory or half-life parameters assessed in the present study. Similarly, neither the insulinogenic ratio (tAUC insulin:tAUC glucose) nor the glucose:insulin ratio provides support for an insulinotropic effect in the $6 \mathrm{M}_{\mathrm{HP}}$ condition in the present study. Indeed, there was a trend for the glucose:insulin ratio to be higher in the $6 \mathrm{M}_{\mathrm{HP}}$ condition (Fig. 5(a)), translating into extended periods throughout the day (approximately $120 \mathrm{~min}$ in the morning and approximately $80 \mathrm{~min}$ in the afternoon; Fig. 5(c)), while the glucose:insulin ratio was elevated (insulinotropic effect would result in a reduction of this ratio).

Other mechanisms associated with the hypoglycaemic effect of protein are suggested to be due to differences in gastric emptying $^{(8)}$ or enhanced insulin secretion through augmented GIP and glucagon-like peptide 2 secretion $^{(9)}$. Frid et al. ${ }^{(30)}$ observed that postprandial GIP responses were higher after ingestion of whey than after that of a reference meal containing no whey (alternate source of protein). While we observed no differences in GIP levels between study days $\left(6 \mathrm{M} v \cdot 6 \mathrm{M}_{\mathrm{HP}}\right)$, it is important to note that the present study substituted protein for carbohydrate as opposed to adding it to the meal. Thus, the lack of a significant difference between the $6 \mathrm{M}_{\mathrm{HP}}$ and $6 \mathrm{M}$ regimens is surprising. Finally, it is of interest to note the appearance of a possible diurnal trend in the GIP responses to meals in the present study, with a trend for an increasing peak GIP response at subsequent meals 

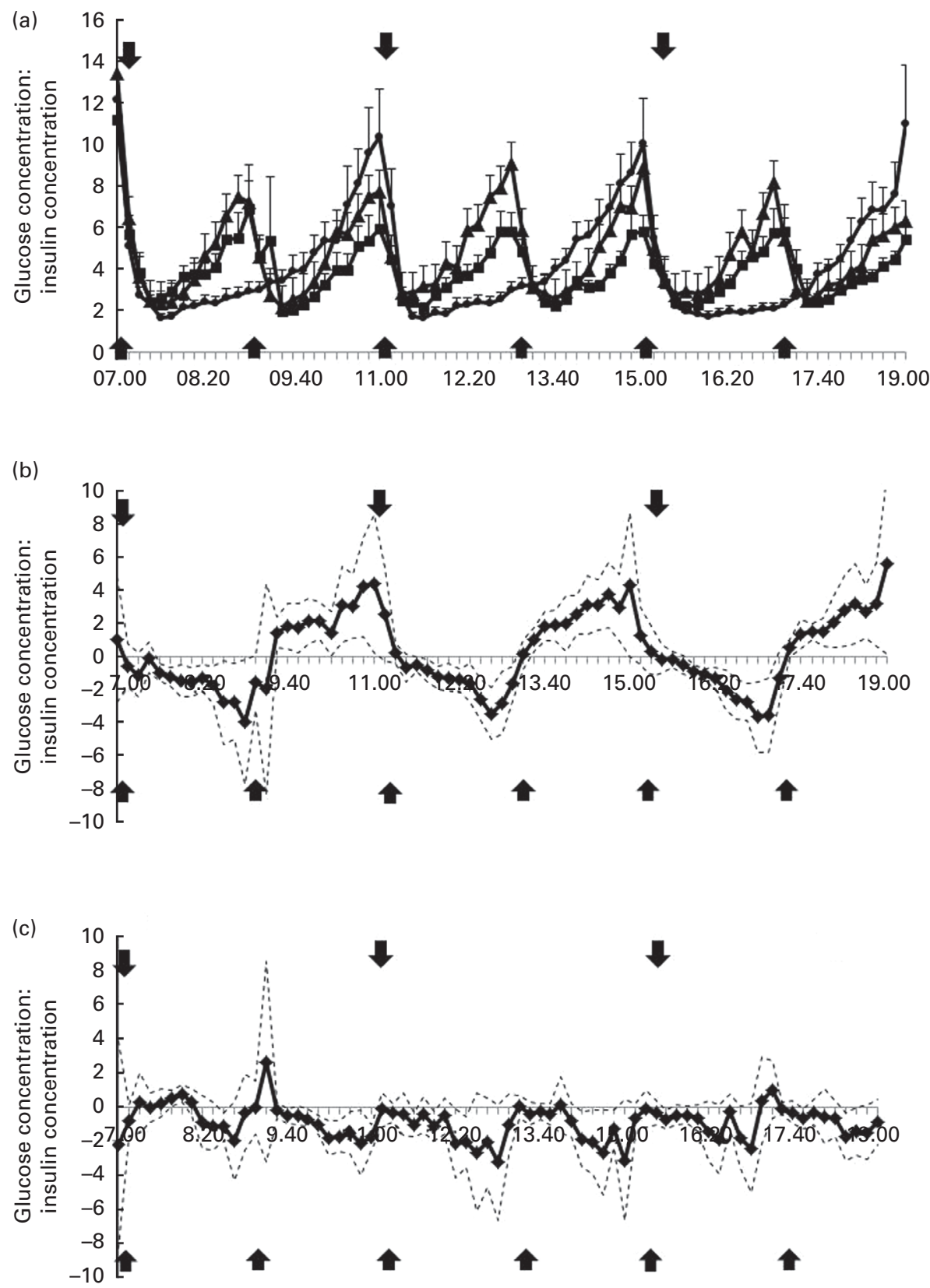

Fig. 5. (a) Patterns of the ratio of glucose concentration:insulin concentration over $12 \mathrm{~h}$ for each study day, (b) comparison of the low-frequency meal minus high-frequency meal $(6 \mathrm{M})$ ratio of glucose concentration:insulin concentration and (c) comparison of the $6 \mathrm{M}$ minus high-frequency, high-protein meal ratio of glucose concentration:insulin concentration. More details are given in Fig. 3. ^, Meal. To convert glucose/insulin in $\mathrm{mg}$ per $\mathrm{dl} / \mu \mathrm{IU}$ per $\mathrm{ml}$ to $\mathrm{mmol}$ per l/pmol per I, multiply by 0.00801 .

(Fig. 1(c)). While a more rapid early GIP response following ingestion of a standardised meal in the morning compared with the afternoon (AUC in the first $30 \mathrm{~min}$ after meal ingestion) was observed in healthy subjects in previous research, there were no differences in GIP concentrations in the remaining $270 \mathrm{~min}^{(31)}$ or peak GIP concentrations. Further investigation into GIP responses over the course of the day in both healthy and clinical populations would be of interest.

Surprisingly, there are a limited number of studies that have examined postprandial glycaemic control in response to different meal frequency patterns, and these have utilised discernible study protocols. The strength of the present study is that we assessed this response over a $12 \mathrm{~h}$ period and captured possible diurnal variations in glucose tolerance ${ }^{(28)}$. Furthermore, the frequent sampling techniques allowed us to more carefully analyse the pattern of responses compared with some of the previous studies that have sampled hourly ${ }^{(10,13)}$. In addition, many of the previous studies have recruited only lean healthy individuals ${ }^{(10,12)}$, and the study that did recruit individuals with T2D recruited a heterogeneous group based on age, sex and body weight status $^{(13)}$. One limitation of the present study is that we did 
not include a $3 \mathrm{M}_{\mathrm{HP}}$ trial. We did not include this group as the present study was modelled after our previous study in lean subjects $^{(11)}$. In hindsight, this arm would have allowed us to establish the effect of meal frequency on the HP condition. In addition, it could be argued that we should have included more energy in the meals, as larger meals may more closely reflect what these subjects habitually consume; however, we selected an energy intake that would keep these subjects in energy balance during the study day in light of the fact that they were physically inactive all day. In addition, the results represent the short-term response to meal frequency and composition and provide insights into the glycaemic responses. However, the present study does not identify whether the beneficial responses observed with a $6 \mathrm{M}$ pattern would still be manifested in a long-term study. Future research needs to address whether long-term changes in meal frequency alter insulin sensitivity.

The present study demonstrated that in an obese population ingestion of more frequent meals (six-meal eating pattern $v$. three-meal eating pattern) (1) results in no change in glucose tAUC despite significantly lower insulin tAUC and (2) reduces postprandial insulin excursions without altering C-peptide secretory parameters or GIP tAUC. Further research is needed in individuals with T2D to establish the effects of long-term ramifications of adopting frequent meal patterns on insulin sensitivity, clearance and secretion. Furthermore, the substitution of carbohydrates with protein reduces insulin and glucose tAUC and does not alter the glucose:insulin ratio, secretory parameters for C-peptide or GIP responses. Finally, no significant diurnal patterns emerged across any of the parameters investigated in the present study.

\section{Acknowledgements}

The authors cordially thank the subjects for contributing a tremendous amount of their time to the present study and the nurses on the Clinical Research Unit at the University of Missouri.

The present study was partially supported by NIH R21DK084467. The NIH had no role in the design and analysis of the study or in the writing of this article.

The authors' contributions are as follows: J. A. K. conceived the study, designed the research, conducted the research, analysed the data, edited the final version of the article, and had primary responsibility for the final content of article; T. D. H. conducted the research, analysed the data, and edited the final version of the article; Y. L. conducted the research and analysed the data; T. J. F. conceived the study, designed the research, analysed the data, and edited the final version of article.

None of the authors has any conflicts of interest to declare.

\section{References}

1. Pories WJ, MacDonald KG Jr, Morgan EJ, et al. (1992) Surgical treatment of obesity and its effect on diabetes: 10-y follow-up. Am J Clin Nutr 55, Suppl. 2, 582S-585S.
2. Reed MA, Pories WJ, Chapman W, et al. (2011) Roux-en-Y gastric bypass corrects hyperinsulinemia implications for the remission of type 2 diabetes. J Clin Endocrinol Metab 96, 2525-2531.

3. Schulze MB, Thorand B, Fritsche A, et al. (2012) Body adiposity index, body fat content and incidence of type 2 diabetes. Diabetologia 55, 1660-1667.

4. Zarjevski N, Doyle P \& Jeanrenaud B (1992) Muscle insulin resistance may not be a primary etiological factor in the genetically obese fa/fa rat. Endocrinology 130, 1564-1570.

5. Alemzadeh R, Jacobs W \& Pitukcheewanont P (1996) Antiobesity effect of diazoxide in obese Zucker rats. Metabolism 45, 334-341.

6. Alemzadeh R, Langley G, Upchurch L, et al. (1998) Beneficial effect of diazoxide in obese hyperinsulinemic adults. J Clin Endocrinol Metab 83, 1911-1915.

7. Corkey BE (2012) Banting lecture 2011: hyperinsulinemia: cause or consequence? Diabetes 61, 4-13.

8. Pories WJ \& Dohm GL (2012) Diabetes: have we got it all wrong? Hyperinsulinism as the culprit: surgery provides the evidence. Diabetes Care 35, 2438-2442.

9. Rizza RA, Mandarino LJ, Genest J, et al. (1985) Production of insulin resistance by hyperinsulinaemia in man. Diabetologia 28, 70-75.

10. Munsters MJ \& Saris WH (2012) Effects of meal frequency on metabolic profiles and substrate partitioning in lean healthy males. PLOS ONE 7, e38632.

11. Holmstrup M, Owens C, Fairchild T, et al. (2010) Effect of meal frequency on glucose and insulin excursions over the course of a day. e-SPEN 5, e277-e280.

12. Solomon TP, Chambers ES, Jeukendrup AE, et al. (2008) The effect of feeding frequency on insulin and ghrelin responses in human subjects. Br J Nutr 100, 810-819.

13. Jenkins DJ, Ocana A, Jenkins AL, et al. (1992) Metabolic advantages of spreading the nutrient load: effects of increased meal frequency in non-insulin-dependent diabetes. Am J Clin Nutr 55, 461-467.

14. Kalogeropoulou D, Lafave L, Schweim K, et al. (2008) Leucine, when ingested with glucose, synergistically stimulates insulin secretion and lowers blood glucose. Metabolism 57, 1747-1752.

15. Gannon MC \& Nuttall FQ (2004) Effect of a high-protein, low-carbohydrate diet on blood glucose control in people with type 2 diabetes. Diabetes 53, 2375-2382.

16. Lan-Pidhainy X \& Wolever TM (2010) The hypoglycemic effect of fat and protein is not attenuated by insulin resistance. Am J Clin Nutr 91, 98-105.

17. Heden TD, Liu Y, Sims LJ, et al. (2013) Meal frequency differentially alters postprandial triacylglycerol and insulin concentrations in obese women. Obesity (Silver Spring) 21, 123-129.

18. Goetze O, Steingoetter A, Menne D, et al. (2007) The effect of macronutrients on gastric volume responses and gastric emptying in humans: a magnetic resonance imaging study. Am J Physiol Gastrointest Liver Physiol 292, G11-G17.

19. Matthews DR, Hosker JP, Rudenski AS, et al. (1985) Homeostasis model assessment: insulin resistance and $\beta$-cell function from fasting plasma glucose and insulin concentrations in man. Diabetologia 28, 412-419.

20. Katz A, Nambi SS, Mather K, et al. (2000) Quantitative insulin sensitivity check index: a simple, accurate method for assessing insulin sensitivity in humans. J Clin Endocrinol Metab 85, 2402-2410.

21. Pruessner JC, Kirschbaum C, Meinlschmid G, et al. (2003) Two formulas for computation of the area under the curve represent measures of total hormone concentration 
versus time-dependent change. Psychoneuroendocrinology 28, 916-931.

22. Engdahl JH, Veldhuis JD \& Farrell PA (1995) Altered pulsatile insulin secretion associated with endurance training. J Appl Physiol 79, 1977-1985.

23. Johnson ML, Veldhuis PP, Grimmichova T, et al. (2010) Validation of a deconvolution procedure (AutoDecon) for identification and characterization of fasting insulin secretory bursts. J Diabetes Sci Technol 4, 1205-1213.

24. Pritzlaff CJ, Wideman L, Weltman JY, et al. (1999) Impact of acute exercise intensity on pulsatile growth hormone release in men. J Appl Physiol 87, 498-504.

25. Kanaley JA, Weltman JY, Pieper KS, et al. (2001) Cortisol and growth hormone responses to exercise at different times of day. J Clin Endocrinol Metab 86, 2881-2889.

26. Corkey BE (2012) Diabetes: have we got it all wrong? Insulin hypersecretion and food additives: cause of obesity and diabetes? Diabetes Care 35, 2432-2437.
27. Saad A, Dalla Man C, Nandy DK, et al. (2012) Diurnal pattern to insulin secretion and insulin action in healthy individuals. Diabetes 61, 2691-2700.

28. Van Cauter E, Shapiro ET, Tillil H, et al. (1992) Circadian modulation of glucose and insulin responses to meals: relationship to cortisol rhythm. Am J Physiol 262, E467-E475.

29. Lee A, Ader M, Bray GA, et al. (1992) Diurnal variation in glucose tolerance. Cyclic suppression of insulin action and insulin secretion in normal-weight, but not obese, subjects. Diabetes 41, 750-759.

30. Frid AH, Nilsson M, Holst JJ, et al. (2005) Effect of whey on blood glucose and insulin responses to composite breakfast and lunch meals in type 2 diabetic subjects. Am J Clin Nutr 82, 69-75.

31. Lindgren O, Mari A, Deacon CF, et al. (2009) Differential islet and incretin hormone responses in morning versus afternoon after standardized meal in healthy men. $J$ Clin Endocrinol Metab 94, 2887-2892. 